\title{
Identificación microbiológica de marchitez vascular en col china (Brassica campestris L. var pekinensis) en Cogua, Colombia
}

\author{
Ligia Sánchez ${ }^{1}$, Yesid Ariza ${ }^{1}$, Estefania Castañeda ${ }^{1}$, Edgar Martinez ${ }^{2}$
}

\author{
1.Universidad Colegio Mayor de Cundinamarca, Bogotá, Colombia \\ 2. Universidad de Ciencias Aplicadas y Ambientales, Bogotá, Colombia \\ Correspondencia: ligiasanchezle@gmail.com
}

Recibido: 25-08-10/ Aceptado: 27-11-10

\section{Resumen}

La col china (Brassica campestris L. var pekinensis) es una hortaliza de origen asiático apreciada en todos los continentes por su valor nutricional y propiedades medicinales. Reportes de productores de todo el país han manifestado que hay pérdidas económicas en este cultivo al parecer originadas por enfermedades bacterianas; una de ellas es la marchitez bacteriana, que disminuye el tiempo de viabilidad del producto, también su continuidad en el mercado y, en consecuencia, la no utilización del mismo por parte del consumidor. Cultivadores en Cogua, Colombia reportan pérdidas de un $80 \%$ en su producción a causa de esta patología. La principal manifestación es la presencia de lesiones húmedas y marchitez en los bordes externos de las hojas.

El objetivo de este proyecto fue la identificación microbiológica de los posibles patógenos de la marchitez bacteriana en un cultivo de col china en Cogua, Colombia. La metodología utilizada incluyó el análisis de los microorganismos presentes en plantas sanas y enfermas, el aislamiento de bacterias de las lesiones vasculares, la elaboración de pruebas de patogenicidad y la identificación fenotípica del patógeno. Los resultados permitieron concluir que el microorganismo patógeno que ocasionaba marchitez bacteriana en los cultivos de col china en Cogua, Colombia era Xanthomonas axonopodis. La identificación de patógenos en plantas de interés económico permite tomar medidas más eficientes referentes a las buenas prácticas agrícolas para manejar enfermedades en plantas y disminuir las pérdidas de producción. Palabras clave: col china, flavonoides, fitopatología, marchitez vascular, Xanthomonas.

\section{Abstract \\ Microbiological identification of vascular wilt in Chinese cabbage (Brassica campestris L. var pekinensis) in Cogua, Colombia \\ Chinese cabbage (Brassica campestris L. var pekinensis) is an Asian vegetable appreciated in all continents for its nutritional value and medicinal properties. Reports from farmers across the country have shown that there are economic losses in this crop apparently caused by bacterial diseases, one of which is bacterial wilt, which decreases the time of viability of the product also its continuity in the market and therefore, non-use by the consumer. Growers in Cogua, Colombia reported an $80 \%$ loss}


in production due to this disease. The main symptom is the presence of moist lesions and wilting on the outer edges of the leaves.

The objective of this project was the identification of potential microbiological pathogens of bacterial wilt in a Chinese cabbage crop in Cogua, Colombia. The methodology included the analysis of microorganisms in healthy and diseased plants, isolation of bacteria in the vascular lesions, the development of pathogenicity and phenotypic identification of the pathogen. The results concluded that the pathogen that caused bacterial wilt on crops of Chinese cabbage in Cogua, Colombia was Xanthomonas axonopodis. The identification of pathogens in plants of economic interest can take more effective measures relating to good agricultural practices to manage diseases in plants and reduce production losses.

Keywords: Chinese cabbage, flavonoids, plant pathology, vascular wilt, Xanthomonas.

\section{Introducción}

En el ámbito mundial, las hortalizas son un grupo de plantas muy variado con gran capacidad de comercialización debido a su contenido de aminoácidos, de vitaminas y de minerales (1). Actualmente, los vegetales han adquirido importancia por el cambio en los hábitos alimenticios que se orientan hacia el consumo de productos naturales con miras a mejorar la calidad de vida de personas sanas o que sufran alguna enfermedad terminal (2). Las especies de la familia Cruciferae son bien conocidas por la gastronomía y la medicina alternativa: brócoli (Brassica oleraceae L. Subs. itálica Plenck), coliflor (Brassica oleraceae L. Subs. botrytis L), repollitas o coles de Bruselas (Brassica oleraceae L. Subs. gernmifera DC), nabo (Brassica rapa L. Subs. Rapifera), y col china (Brassica campestris L. Subs. pekinensis) $(1,3)$.

La col china, originaria del Norte de China (4) es una de las especies promisorias en Colombia, se adapta muy bien al clima frío, se desarrolla en óptimas condiciones en suelos ricos en nitrógeno y potasio, humedad y temperatura que favorecen la floración temprana (5). Se ha indicado que un alto consumo de los productos de la planta están asociados a la disminución de enfermedades crónicas, como las cardiovasculares, la diabetes y el cáncer (6-8), debido a la presencia de antioxidantes, vitamina $\mathrm{C}$, vitamina $\mathrm{E}$, carotenoides, glucosinolatos y compuestos fenólicos, especialmente flavonoides que en años recientes, ha contribuido a mejorar la calidad de vida del ser humano.

En Colombia, la demanda del producto corresponde a estratos medios y altos; destino actual de este producto son supermercados de cadena y su comercialización es relativamente rápida. El Ministerio de Agricultura y Desarrollo Rural ha estimulado la participación de productores de hortalizas en los últimos años consolidando un acuerdo de competitividad (9). En este documento se reporta que el mercado de coles y coliflores es bajo, pero también que los productores de la región cundiboyacense, por la demanda de los consumidores, han aumentado su producción progresivamente en los últimos cinco años.

El mayor problema del cultivo de coles mundialmente, es la marchitez vascular producida por bacterias (10-12), en el caso concreto de la col china, es un grave problema, pues son las hojas el producto consumible de este vegetal. Trabajos previos en otros países han identificado que Xanthomonas es el género bacteriano más asociado a la pudrición de las crucíferas (5). El mecanismo de patogenicidad de Xanthomonas parece estar asociado al sistema de secreción tipo III (13-15), que es propio de las bacterias Gram negativas y que parece estar relacionado con respuestas específicas gen por gen entre las plantas y los bacilos Gram negativos lo que 
podría explicar porqué las plantas son atacadas casi exclusivamente por bacilos Gram negativos tipo Pseudomonas, Xanthomonas y Erwinia, entre otros $(16,17)$.

Se sabe también que en el caso particular de Xanthomonas se produce un pigmento amarillo conocido como xanthomonadina, que es un componente químico taxonómico que facilita su diagnóstico y le confiere protección contra los daños foto-biológicos; también es indicador de patogenicidad (18). Se ha determinado la presencia de una feromona en esta especie que es necesaria para la producción de su polisacárido extracelular (EPS) y de sus dos tipos de pigmentos (pig A y pig G), indispensable para la supervivencia en el huésped y que juegan un papel determinante en la infección del hospedero y/o supervivencia en la planta (19-21).

Los productores del municipio de Cogua, en la sabana de Bogotá, han reportado pérdidas debidas a una enfermedad que se caracteriza por lesiones que son comparables con las reportadas para infecciones bacterianas por Xanthomonas en algunas variedades de hortalizas. La mayoría de las investigaciones en el país se han orientado al diagnóstico y control de patologías producidas por hongos, comunes en otras variedades vegetales y por lo tanto no hay un modelo de diagnóstico y control de patologías bacterianas que permita implementar medidas de control eficaces que mitiguen las pérdidas económicas por esta enfermedad bacteriana.

Con este trabajo se espera hacer un aporte sobre el conocimiento del tipo de microorganismo bacteriano que está causando marchitez vascular en los cultivos de col china en Cogua, municipio de Cundinamarca, Colombia, para controlar su diseminación, tomar medidas de control eficientes en lo que se refiere a buenas prácticas agrícolas (BPA), a dar apropiado uso a los plaguicidas y a buscar alternativas de control fitoquímico o biológico frente a la enfermedad, y de esta manera conservar las características del producto consumible, sin alterar el equilibrio natural del medio en que se desarrollan, mejorando la calidad y eficiencia del cultivo, lograr mayor rentabilidad económica, un producto más acorde con las exigencias del mercado y disminuir la incidencia de la enfermedad en el territorio nacional.

\section{Materiales y métodos}

\section{Fase 1. Aislamiento e identificación microbiológica}

Toma de muestras: se seleccionaron 10 plantas enfermas y 10 sanas de los cultivos de col china (Brassica campestris sbp pekinensis) procedentes de Cogua, Cundinamarca, utilizando un muestreo aleatorio simple haciendo un cubrimiento de todo el terreno. Las muestras se envolvieron en hojas de papel y se protegieron con bolsas de polietileno y se transportaron para el análisis correspondiente antes de una hora.

Procesamiento de las muestras: se procedió a detectar la presencia bacteriana según el protocolo de Mendoza y Castaño (21). 1. Lavar las muestras de col china, sanas y enfermas con agua corriente durante varios minutos a fin de eliminar contaminantes. 2 . Seleccionar las hojas más afectadas de las plantas enfermas y las hojas de las plantas sanas. 3. Hacer un corte fino de $1 \mathrm{~mm}^{2}$ del tejido más próximo al área necrosada. 4. Realizar un montaje húmedo y observar al microscopio la salida del flujo bacterial del tejido vegetal afectado para comprobar la presencia de microorganismos bacterianos. 5. Aislar y purificar las bacterias obtenidas.

\section{Aislamiento y purificación de bacterias:} 1. Realizar un corte del área aproximada a las áreas necrosadas de las hojas de plantas enfermas y de las hojas de plantas sanas de col china, de aproximadamente $1 \mathrm{~mm}$ de ancho y $3 \mathrm{~mm}$ de longitud. 2. Picar finamente en condiciones de asepsia. 3. Lavar 3 veces en agua destilada estéril. 4. Trasladar a un tubo con $200 \mu \mathrm{L}$ de agua destilada estéril y se dejar reposar por 4 minutos para permitir que las bacterias fluyeran al líquido. Este procedimiento se repitió para cada una de las muestras. Con un asa bacteriológica calibrada se tomó una muestra de la suspensión y se procedió a realizar una siembra masiva en agar tripticase de soya, agar extracto de 
col china (ver preparación) y agar McConkey por triplicado para cada una de las muestras. Se incubaron entre $26^{\circ} \mathrm{C}$ y $28^{\circ} \mathrm{C}$ de temperatura por 48 horas. Una vez obtenido el crecimiento se realizó una identificación microscópica por coloración de Gram y se establecieron las características macroscópicas de las colonias aisladas.

Preparación del agar extracto de col china: Seleccionar cinco plántulas jóvenes y sanas de col china, lavar con agua corriente y posteriormente enjuagar con agua destilada estéril cuatro veces. Pesar 80 gr de las hojas, macerarlas con $200 \mathrm{~mL}$ de agua destilada en un mortero estéril hasta obtener una cantidad suficiente del macerado. Cubrir el mortero y dejarlo en un ambiente seco y ausente de luz durante $48 \mathrm{~h}$. Luego filtrar en un erlenmeyer el contenido del extracto y agregar 2 gr de agar- agar. Esterilizar en autoclave por 15 minutos a 121 libras de presión, enfriar y servir en cajas de Petri hasta la solidificación del medio.

\section{Fase 2. Identificación fenotípica de los microorganismos aislados}

Las colonias puras obtenidas fueron sometidas a una prueba de identificación bioquímica utilizando el sistema de pruebas automatizadas BD BBL Crystal. Identification System Enteric/Nonfermenter ID Kit. Como pruebas complementarias se realizaron: catalasa; oxidasa; nitrato; indol; urea; Voges-Proskauer; hidrólisis de gelatina; esculina; descarboxilación de aminoácidos (ornitina, arginina y lisina); motilidad; producción de pigmento; fermentación de azúcares OF (galactosa, arabinosa, manosa, fructuosa). Las pruebas fueron leídas después de 48 horas de incubación entre $26^{\circ} \mathrm{C}$ y $28^{\circ} \mathrm{C}$.

\section{Fase 3. Pruebas de patogenicidad}

Estudio experimental utilizando línea base múltiple intersujeto de tipo A y B.

Diseño muestral: siembra total 104 plántulas. De un total de 52 muestras procedentes del municipio de Cogua, susceptibles a presentar la enfermedad (controles) y 52 muestras de col china sanas (experimentales), se estableció un control de la evolución de la enfermedad bajo dos etapas que se analizaron de forma paralela.

\section{Caracterización de síntomas en cultivo de col} china: las muestras, presentaban lesiones húmedas (S1), marchitez sobre los bordes externos con disposición regular sobre las hojas (S2), infiriendo que las bacterias penetraron principalmente por los hidátodos como consecuencia de previas lesiones por plagas. Afección endófita.

Etapa A: observación del crecimiento de las plántulas controladas en condiciones de invernadero, a temperatura y humedad, comparando criterios de presencia o ausencia de los síntomas de la enfermedad en cada una de las muestras; se realizaron observaciones cada 48 horas entre las 3 y 4 de la tarde, durante 15 días en curso a partir del 1 de mayo del 2008. De la misma forma se llevaron a cabo las observaciones para 52 plantas del cultivo del municipio de Cogua, Cundinamarca, comparando los resultados obtenidos.

Etapa B: número de plantas inoculadas con el patógeno, bajo una concentración mínima, Escala de Mc Farland 1 y Escala de Mc Farland 4 por el método de punción sobre las hojas, para comparar la evolución del proceso infeccioso evaluando el comportamiento de las poblaciones por competitividad de nutrientes de acuerdo a la relación huésped-hospedador durante las 48, 72 y $96 \mathrm{~h}$.

Preparación de la biomasa: se preparó a partir de colonias aisladas de agar extracto col china con 48 horas de incubación en caldo BHI con agitación constante a $200 \mathrm{rpm}$ durante 24 horas. Posteriormente la suspensión bacteriana se preparó con una hora antes de la inoculación en agua destilada esterilizada a escala de Mac Farland $1\left(3 \times 10^{6} \mathrm{~mL}\right)$ y $4\left(12 \times 10^{6} \mathrm{~mL}\right)$.

Disposición de las plantas: se sembraron con 15 días de anticipación bajo condiciones de invernadero a una humedad relativa mayor a $80 \%$ y temperatura 
Tabla 1. Pruebas bioquímicas para identificación de Xanthomonas axonopodis.

\begin{tabular}{llll}
\hline Pruebas bioquímicas & & & \\
\hline Catalasa & Positivo & Esculina & Positivo \\
\hline Red. nitrato & Negativo & Gelatina & Negativo \\
\hline Indol/oxidasa & Negativo & Motilidad & Positiva \\
\hline Voges Proskauer & Negativo & Ornitina & Negativo \\
Urea & Negativo & Arginina & Negativo \\
Hidrólisis & Positiva & Prod. Pigmento Positivo \\
\hline Galactosa & Negativo & Manosa & Negativo \\
\hline Arabinosa & Negativo & Fructuosa & Negativo \\
\hline
\end{tabular}

entre $25^{\circ} \mathrm{C}$ y30 ${ }^{\circ} \mathrm{C}$, garantizando su crecimiento óptimo y disminuyendo la susceptibilidad a daños por plagas u otros microorganismos fitopatógenos.

Inoculación: la limpieza se realizó en condiciones de asepsia con hipoclorito de sodio al 5\% a cada una de las hojas de la planta (10 hojas), posteriormente con agua destilada esterilizada para evitar cualquier grado de residualidad del sanitizante. Mediante punción con lancetas estériles se seleccionaron las hojas más jóvenes para realizar la respectiva inoculación. El corte fue realizado en dos sitios de la hoja proximal a la zona vascular de la planta de un $1 \mathrm{~cm}$ de diámetro, para facilitar la diseminación del patógeno. Con jerin-

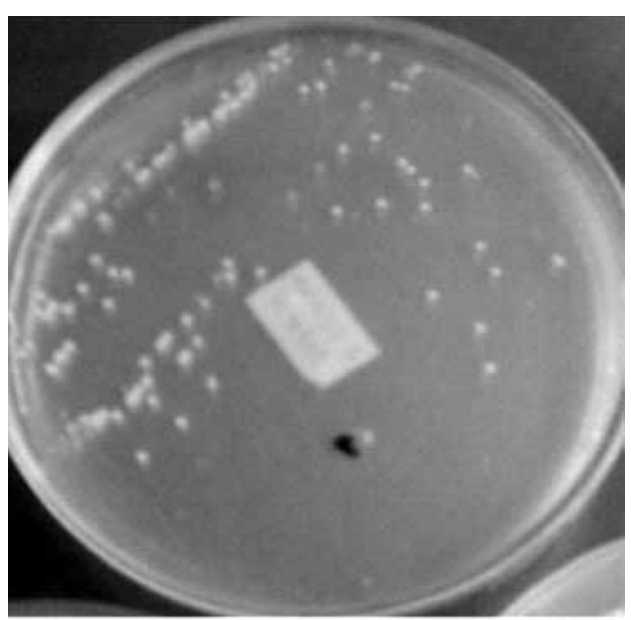

Figura 1. Aislamiento colonias bacterianas pertenecientes al género Xanthomonas. Fuente: Agón y Castañeda, 2008. ga estéril, se aplicó $0.2 \mathrm{~mL}$ de la suspensión bacterial en cada herida, a 20 plantas con Escala Mc Farland 1 y a 20 con Escala Mc Farland 4. A fin de incrementar la humedad del ambiente, se utilizaron bolsas plásticas para empacar cada muestra (10 plantas), con el mismo procedimiento de inoculación se dejaron al medio ambiente sin el uso de bolsas plásticas. Se emplearon 12 muestras testigos, cada una de las cuales recibió el mismo tratamiento que las muestras anteriores, a excepción de la inoculación con la suspensión bacteriana.

\section{Identificación fenotípica del patógeno.}

Se procedió de la misma forma que en la fase dos, a partir de las muestras inoculadas que presentaron los síntomas de humedad y marchitez bacteriana respectivas a las pruebas de patogenicidad.

\section{Resultados}

Fase 1: Aislamiento e Identificación microbiológica. Se aislaron colonias redondas, brillantes, de aspecto liso, bordes enteros y color blanco en agar tripticase de soya y amarillas en agar extracto de col china. Figura 1. La tinción de Gram evidenció Bacilos Gram negativos, delgados y cortos, Figura 2.

\section{Fase 2: Identificación fenotípica de los mi-}



Figura 2. Bacilos Gram negativos con coloración de Gram. Fuente: Agón y Castañeda, 2008. croorganismos aislados. Mediante la identificación con el sistema rápido BBL CRYSTAL: prueba oxidasa e indol, se obtuvo un resultado presuntivo con el 90\% de confiabilidad de: Xanthomonas spp. Las pruebas bioquímicas fueron compatibles con Xanthomonas axonopodis, como se puede observar en la Tabla 1. 
Tabla 2. Control de pruebas de patogenicidad.

\begin{tabular}{|c|c|c|c|c|c|c|c|c|c|c|c|c|}
\hline \multirow{3}{*}{$\begin{array}{l}\text { No Planta } \\
\text { Hrs }\end{array}$} & \multicolumn{6}{|c|}{ INVERNADERO } & \multicolumn{6}{|c|}{ AMBIENTE } \\
\hline & \multicolumn{3}{|c|}{ Esc. Mc Farland I } & \multicolumn{3}{|c|}{ Esc. Mc Farland 4} & \multicolumn{3}{|c|}{ Esc. Mc Farland I } & \multicolumn{3}{|c|}{ Esc. Mc Farland 4} \\
\hline & 48 & 72 & 96 & 48 & 72 & 96 & 48 & 72 & 96 & 48 & 72 & 96 \\
\hline I & $0 \%$ & $0 \%$ & $0 \%$ & $0 \%$ & $0 \%$ & $0 \%$ & $0 \%$ & $0 \%$ & $0 \%$ & $0 \%$ & $0 \%$ & $0 \%$ \\
\hline 2 & $0 \%$ & $0 \%$ & $0 \%$ & $0 \%$ & $0 \%$ & $0 \%$ & $0 \%$ & $0 \%$ & $0 \%$ & $0 \%$ & $0 \%$ & $0 \%$ \\
\hline 3 & $0 \%$ & $0 \%$ & $0 \%$ & $0 \%$ & $0 \%$ & $0 \%$ & $0 \%$ & $0 \%$ & $0 \%$ & $0 \%$ & $0 \%$ & $0 \%$ \\
\hline
\end{tabular}

Fase 3. Pruebas de patogenicidad. En las pruebas de patogenicidad, etapa A, las plántulas sembradas y controladas durante 15 días fueron completamente sanas en comparación con las 52 plantas bajo observación, presentes en el cultivo de Cogua, que en su gran mayoría presentaron lesiones húmedas y marchitez que aumentaron progresivamente. En la etapa B, posterior a la inoculación de las hortalizas sanas con Xanthomonas axonopodis, se evidenciaron los síntomas específicos de la enfermedad a las $48 \mathrm{~h}$, con un porcentaje de infección variable de acuerdo a las concentraciones Escala de Mac Farland 1 con un aumento progresivo a las $72 \mathrm{~h}$ y $96 \mathrm{~h}$. Mientras que en la escala 4 de Mac Farland, hubo menor porcentaje de infección, Figura 2. Durante la fase de confirmación del patógeno, aislado de las hortalizas infectadas en las pruebas de patogenicidad, se evidenció que la Xanthomonas axonopodis es el agente causal del proceso infeccioso en col china de los cultivos de Cogua, Cundinamarca, Tabla 2.

\section{Discusión}

Durante la fase inicial de la investigación, el aislamiento de las lesiones húmedas y de marchitez de 10 plantas enfermas de col china evidenció la presencia de colonias, con características morfológicas in vitro: colonias redondas, brillantes, de aspecto liso, bordes enteros y color blanco o amarillo en agar tripticasa de soya y agar extracto de col china, este último favoreció su crecimiento por las condiciones nutricionales de la misma planta. A partir de la coloración de Gram, se observaron bacilos Gram negativos, delgados y cortos. Las plantas sin lesiones

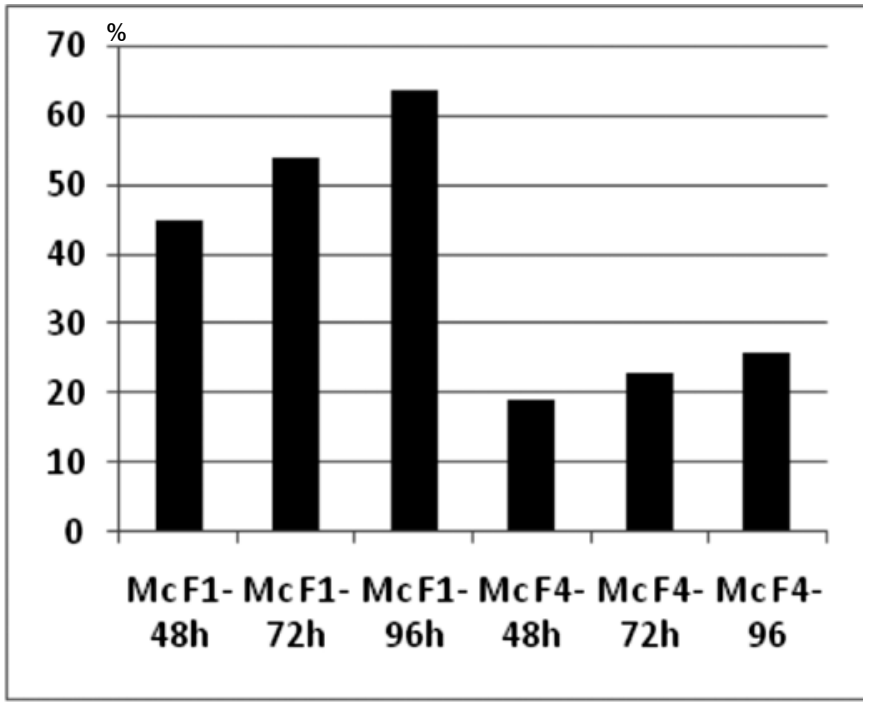

Figura 2. Porcentaje de infección en plántulas inoculadas con Xanthomonas axonopodis.

no presentaron crecimiento bacteriano. Mediante la identificación rápida con BBL CRYSTAL: prueba de oxidasa e indol, se obtuvo un resultado presuntivo con el $90 \%$ de confiabilidad de: Xanthomonas spp. Las pruebas bioquímicas fueron compatibles con Xanthomonas axonopodis.

Los resultados obtenidos en este trabajo permiten establecer que el proceso infeccioso en los cultivos de col china ubicados en el municipio de Cogua, Cundinamarca, fueron ocasionados por una bacteria fitopatógena perteneciente a la familia Pseudomonacea, género Xanthomonas, especie axonopodis. La infección se estableció por el ingresó de forma endófita del microorganismo a la planta por medio de los vasos conductores de la savia, provocando humedad y marchitez en los extremos de las hojas que se van diseminando lentamente generando un daño considerable en la col china. 
En las pruebas de patogenicidad se observaron los síntomas específicos de la enfermedad con un crecimiento constante en relación al tiempo en el que fueron realizadas las observaciones. Sin embargo, la concentración del inoculo influye directamente en el porcentaje de infección $(22,23)$, teniendo presente que las plantas inoculadas con escala $1 \mathrm{Mc}$ Farland es mayor en comparación con aquellas manejadas a escala $4 \mathrm{Mc}$ Farland. El término de densidad de poblaciones es un parámetro determinante para explicar este fenómeno.

Es evidente que la relación microorganismonutriente determina la supervivencia de Xanthomonas axonopodis en el huésped. Como complemento a este trabajo será importante realizar una curva de crecimiento de la bacteria aislada para establecer las diferente fases de crecimiento partiendo de la densidad microbiana de la escala de Mc Farland 1 que fue con la que se obtuvo el mejor resultado de infección. Sin embargo, no pueden desconocerse otros factores relacionados por diversos autores como predisponentes para sufrir la enfermedad, uno de ellos es la susceptibilidad de la planta, otro el potencial patógeno de la bacteria y las condiciones ambientales para su desarrollo $(10,24)$.

Sobre la susceptibilidad de las crucíferas a la infección por Xanthomonas, es importante mencionar que en las pruebas preliminares para definir el medio de cultivo para el crecimiento del microorganismo, inicialmente se realizó el medio con plantas de edad madura y no se obtuvo crecimiento. Posteriormente se utilizaron plántulas jóvenes que fueron las que finalmente se utilizaron en el experimento y con las que se logró un buen crecimiento del patógeno. Esta prueba y los conceptos de la fisiología de plantas reportadas $(25,26)$, permiten inferir que los compuestos fenólicos presentes en col china y otras hortalizas de la familia de las Crucíferas, influyen en la regulación del crecimiento de la bacteria y por lo tanto son los primeros estados vegetativos de la planta los más susceptibles de infección. Esto evidencia el momento en que es más importante reforzar las condiciones de nutrición de la planta y los controles para evitar el ataque del patógeno.
Sobre el potencial de infección de Xanthomonas axonopodis se ha estudiado a fondo el sistema de secreción de efectores tipo III $(27,28)$, desarrollado por las bacterias Gram negativas como estrategia de infección. Este sistema inyecta más de 20 proteínas efectoras en la planta con la cual se establece una relación gen de virulencia - gen de resistencia en donde se ponen en juego las capacidades bioquímicas de la interacción huésped y patógeno (29-32). Este conocimiento permitirá a futuro planear estrategias moleculares para disminuir las pérdidas económicas por este patógeno.

Sobre el factor ambiental y como resultado en esta investigación, se puede afirmar que la humedad y la temperatura aplicados en el experimento si fueron determinantes en el proceso de infección. Estos valores fueron tomados de observaciones realizadas por investigadores de la Universidad de Ciencias Ambientales y Aplicadas UDCA en ensayos preliminares en invernadero. El grupo ha considerado a futuro hacer un estudio de la cinética del microorganismo para conocer su comportamiento de crecimiento, determinar sus genes de virulencia e investigar la microbiota con potencial antagonista como alternativa de control biológico que complemente un manejo integrado de plagas que disminuya las pérdidas de producción de los agricultores de Cogua, municipio de Cundinamarca, Colombia.

\section{Agradecimientos}

A todo el grupo docente de la Universidad Colegio Mayor de Cundinamarca, que colaboró en la elaboración de este trabajo, en especial a la docente Judith Huérfano, quien apoyó en la elaboración de los medios de cultivo especiales para el crecimiento del microorganismo bacteriano en estudio.

\section{Referencias}

1. Bell PR, Hemsley AR. Green Plants: their origin and diversity. $2^{\circ}$ ed. Reino Unido: Cambridge University Press; 2000.

2. Duke JA, Jo Bogenschutz-Godwin M, DuCellier J, Duke P. Handbook of medicinal herbs. $2^{\circ}$ ed. Estados Unidos: CRC Press; 2002.

3. Ebrary Reader. Dixon Geoffrey. R. Vegetable Brassicas and related 
crucifers. Cambridge: CABI publishing. 2006. Julio 2008. Disponible en: http://www.bases.unal.edu.co:2127/lib/unalbog/home.action

4. Prance Sir G, Nesbitt M. The cultural history of plants. New York: Routledge, 2005.

5. Plestsh R. Cultivo del repollo. Instituto Nacional de Tecnología Agropecuaria. Estación Experimental Agropecuaria Corrientes. Agencia de extensión rural corrientes. Argentina. Noviembre 2006. Consultado en Julio 2008. Disponible en: http://www.inta.gov.ar/corrientes/info/ documentos/doc_pagina/El\%20cultivo\%20del\%20Repollo.pdf

6. Podsędek A. Natural antioxidants and antioxidant capacity of Brassica vegetables: A review LWT - Food Science and Technology. 2007;40:1-11.

7. Jung UJ, Baek NI, Chung HG, Bang MH, Jeong TS, Lee KT. et al. Effects of the ethanol extract of the roots of Brassica rapa on glucose and lipid metabolism in C57BL/KsJ-db/db mice. Clin Nutr. 2008;27:158-167.

8. Dong L, Xia S, Gao F, Zhang D, Chen J, Zhang J. 3,3'-Diindolylmethane attenuates experimental arthritis and osteoclastogénesis. Biochem Pharmacol. 2010;79:715-721.

9. Ministerio de Agricultura y Desarrollo Rural. Acuerdo de competitividad de la cadena de Hortalizas. 2006. Consultado en julio de 2008. Disponible en: http://www.antioquia.gov.co/organismos/agricultura/ hortofruticola/hortofruticola/acuerdo $\% 20 \mathrm{de} \% 20$ competitividad.pdf.

10. Ferrera-Cerrato R, Alarcón A. Microbiología Agrícola. México. Trillas. 2007.

11. Anaya S, Romero J. Hortalizas: plagas y enfermedades. México. Trillas. 2007.

12. Agrios G. Fitopatologia. $2^{\circ}$ Ed. México. Grupo Noriega Editores. 2002.

13. Kay S, Bonas U. How Xanthomonas type III effectors manipulate the host plant. Curr Opin Microbiol. 2009;12:37-43.

14. Gurlebeck D, Thieme F, Bonas U. Type III effector proteins from the plant pathogen Xanthomonas and their role in the interaction with the host plant. J Plant Physiol. 2006;163:233-255.

15. Watt TF, Vucur M, Baumgarth B, Watt SA, Niehaus K. Low molecular weight plant extract induces metabolic changes and the secretion of extracellular enzymes, but has a negative effect on the expression of the type-III secretion system in Xanthomonas campestris pv. campestris. J Biotechnol. 2009;140:59-67.

16. Pessarakli M. Handbook of plant and Crop physiology. $2^{\circ}$ ed. Estados Unidos. Marcel Dekker. 2002.

17. Bradbury JF. Guide to plant pathogenic bacteria. Reino Unido. CAB international, Farnharm Royal.1986.

18. Poplawsky AR, Urban SC, Chun W. Biological Role of Xanthomonadin
Pigments in Xanthomonas campestris pv. campestris. Appl Environ Microbiol. 2000;66:5123-5127.

19. Zapata M. Identificación de razas de Xanthomonas campestris pv. phaseoli en hojas de Phaseolus vulgaris. Mesoamericana.1997:8:44-52.

20. Poplawsky AR, Chun W. Xanthomonas campestris pv. campestris requires a functional pigB for epiphytic survival and host infection. Mol Plant Microbe Interact. 1998;11:466-475.

21. Castańo J, Mendoza del Río L. Manual para el diagnóstico de hongos, bacterias, virus y nemátodos fitopatógenos. 1ra Edición. Honduras: Zamorano Academia Press. 1997.

22. Rodríguez C. Microbiología ambiental: manual de laboratorio. Universidad del Quindío. Facultad de Ciencias Básica y Tecnologías. Departamento de Biología. 2000.

23. Bartha R, Atlas R. Ecología microbiana y microbiología ambiental. Madrid 4. Edición. Ed. Addison Wesley, 2002.

24. Reyes P, Reyes CA, Reyes F. Introducción a la Agronomía. México: Editorial Trillas. 2002.

25. Salisbury F, Ross CW. Fisiología de las plantas. Ed. Paraninfo. 2000.

26. Raven PH, Evert RF, Eichhorn SE. Biology of plants. $7^{\circ}$. Edición. New York: Freeman. 2005.

27. Jiang B, He Y, Cen W, Wei H, Jiang G, Jiang W, et al. The type III secretion effector XopXccN of Xanthomonas campestris pv. campestris is required for full virulence. Res Microbiol. 2008;159:216-220.

28. Chang JH, Goel A, Grant S, Dangl J. Wake of the flood: ascribing functions to the wave of type III effector proteins of phytopathogenic bacteria. Curr Opin Microbiol. 2004;7:11-18.

29. Ishihara H, Ponciano G, Leach JE, Tsuyumu S. Functional analysis of the 30 end of avrBs3/pthA genes from two Xanthomonas species. Physiol Mol Plant Pathol. 2003;63:329-338.

30. Gallo M, Ferrari E, Eliseo T, Amata I, Pertinhez T. Katsuyama A. et al. A new member of the ribbon-helix-helix transcription factor superfamily from the plant pathogen Xanthomonas axonopodis pv. citri. J Struct Biol. 2010;170:21-31.

31. Quirino BF, Candido ES, Campos PF, Franco OL, Krüger RH. Proteomic approaches to study plant-pathogen interactions. Phytochemistry. 2010;71: 351-362.

32. Wichmann G, Bergelson J. Effector genes of Xanthomonas axonopodis pv. vesicatoria promote transmission and enhance other fitness traits in the field. Genetics. 2004;166:693-706. 